\title{
Pulmonary complications following cardiac surgery
}

Shahriar Mali ${ }^{1}$, Hasan Haghaninejad ${ }^{2}$

${ }^{1}$ Department of Cardiovascular Surgery, Yazd Cardiovascular Research Centre, Shahid Sadoughi University of Medical Sciences, Yazd, Iran

${ }^{2}$ Department of Cardiology, Yazd Cardiovascular Research Centre, Shahid Sadoughi

University of Medical sciences, Yazd, Iran

Submitted: 26 September 2019

Accepted: 24 October 2019

Arch Med Sci Atheroscler Dis 2019; 4: e280-e285

DOI: https://doi.org/10.5114/amsad.2019.91432

Copyright @ 2019 Termedia \& Banach

\section{Abstract}

Coronary heart disease is a common diseases of atherosclerosis. Despite the development of noninvasive therapies and the advancement of pharmacological methods and extensive drug regimens, coronary artery bypass grafting surgery is still the ultimate treatment option in many patients. Among the various complications following open heart surgery, one of the common difficulties is pulmonary complications associated with subsequent morbidity and mortality, which should be studied according to preoperative, perioperative, and postoperative factors. Preoperative factors include genetics, age, family history of pulmonary disease, smoking, coexisting disease, etc. Perioperative factors include surgical procedures like sternotomy incision, cardioplegia, and internal mammary artery harvesting; anaesthesia procedure effects like pulmonary collapse, maintenance drugs and morphine administration; and cardiopulmonary bypass pump by systemic inflammatory response syndromes. And finally, postoperative factors, especially mediastinitis and the role of nursing in the intensive care unit. Pulmonary complications after cardiac surgery include atelectasis, pleural effusions, pneumonia, pulmonary oedema, cardiogenic pulmonary oedema, acute respiratory distress syndrome, pulmonary embolism, phrenic nerve injury, pneumothorax, sternal wound infection, and mediastinitis, with different outbreaks in patients reported. Although the preoperative, perioperative, and postoperative factors play an important role in the occurrence of these complications, the preoperative factors, as factors that can be adjusted, should be considered more than the others and explained to the patient, and the preoperative patient's assessment should be noted. Also, postoperative care with the goal of reducing infections and pulmonary complications should be addressed by the nursing team.

Key words: pulmonary complications, cardiac surgery, respiratory, cardiovascular.

\section{Introduction}

Cardiovascular disease (CVD) is one of the challenges of medical science not only in developing countries but also in developed countries. Increasing the risk of cardiovascular disease [1-3]. Over time, there is an increase in morbidity and mortality due to CVD. Extensive research suggests an increase in the incidence of atherosclerosis in patients following changes in lifestyle, diet, and genetic and environmental factors such as air pollution. Coronary heart disease (CHD) is one of the common diseases of atherosclerosis, which has been associated with significant

\author{
Corresponding author: \\ Prof. Hasan Haghaninejad \\ Department of Cardiology \\ Yazd Cardiovascular \\ Research Centre \\ Shahid Sadoughi \\ University of \\ Medical Sciences \\ Yazd, Iran \\ E-mail: \\ drhaghaninejadhasan@gmail. \\ com
}


advances in various societies and brings irreparable complications to patients [4-7]. In cases of atherosclerosis, the development of plaques and blood clots in coronary arteries, as well as atherosclerosis, and the risk of heart attacks and tissue necrosis has increased dramatically and causes higher mortality. Despite the development of noninvasive therapies and the advancement of pharmacological methods and extensive drug regimens, coronary artery bypass grafting (CABG) surgery is still the ultimate treatment option in many patients [8-11]. In this method, open heart surgery is performed with or without the use of a cardiopulmonary bypass (CPB) pump, and the vessels are linked. In most cases, this surgery is on pump, which causes the complications of the pump to be imposed on the patient in addition to the various complications of the surgery. Among the various cardiovascular, renal, infectious, and psychiatric complications following open heart surgery, one of the common difficulties is pulmonary complications (PC) associated with subsequent morbidity and mortality [11-14].

The aim of this study was to review PC following cardiac surgery.

\section{Pulmonary complications following cardiac surgery}

As stated, pulmonary complications are an unavoidable complication following CABG surgery $[15,16]$. Various studies have shown a different outbreak in patients ranging from 3 to more than $50 \%[17,18]$. However, the occurrence of PC following cardiopulmonary bypass surgery is a multivariate outcome that should be studied according to the preoperative, perioperative and postoperative. Therefore, we will investigate the effective factors in the occurrence of PC following Cardiac surgery during these periods, and then we will explain the various types of pulmonary diseases following CABG surgery.

\section{Effective factors in the occurrence of PC following cardiac surgery}

\section{Preoperative factors}

Obviously, preoperative factors are the most important prognostic markers for postoperative complications, and in patients undergoing cardiac surgery these factors are even more important. This suggests that the patient's early history and familiarity with patient history play a significant role in managing the patient's postoperative pulmonary conditions. Although the first effective factor in the disease and the complications resulting from their treatment is genetic predisposition, genetic advancements due to the lack of equipment, cost-effectiveness, the uneven distribution of existing tests, and even the reluctance of therapist teams, have not yet been able to accommodate. Human genetics should be the first significant factor in patients and should be attentive to the history of the presence of pulmonary diseases in relatives of a candidate for CABG $[19,20]$. Clinical studies suggest a family history of pulmonary disease as one of the major risk factors for lung disease, and it is evident that cardiac patients undergoing pulmonary complications, if they have a family history of lung disease, will be more at risk. The patient's age is important, not only for the development of PC, but also for all diseases and treatments, and aging is associated with increased morbidity and mortality. A study done on patients over the age of 60 years [21] showed that the prevalence of pulmonary disease in these patients was significantly higher than the lower intervals, and in other studies people over 80 years old had a higher prevalence [22]. This means that preoperative treatment choices should be specifically addressed in these patients. Although PC after CABG surgery is of special interest with high prevalence, if the patient has preoperative pulmonary disease, postoperative PC is significantly high and will require wider strategies. Among the existing pulmonary diseases, it has been shown that patients with chronic obstructive pulmonary disease (COPD) will have more side effects [23]. Another common cause, which is unfortunately a high prevalence in cardiovascular patients, is smoking. Smoking is an important predictor of postoperative $P C$ because in smokers not only pulmonary function tests and lung capacities are significantly changed, but also histologically the destructive effects on patients' lungs has left [24]. In a study of more than 2000 people, it was reported that postoperative PC in smokers (29.5\%) was twice as likely to be the most common in non-smokers $(14.7 \%)$, and in smoking patients the mechanical ventilation required more time, and $6 \mathrm{~h}$ after mechanical ventilation, smokers were more likely to have reflux than non-smokers [25]. In another study, among patients without COPD, only $5.9 \%$ of patients had pulmonary complications after surgery, while $32.2 \%$ of COPD patients had pulmonary complications [26]. Generally, clinical researchers have suggested that quitting smoking at least one year before surgery reduces the risk of post-operative mortality and reduces the risk of arterial and respiratory diseases in current smokers [27]. Obesity is also considered as an effective factor in the incidence of cardiovascular disease as well as pulmonary diseases. A review of various studies has shown that the incidence of PC following CABG surgery in obese patients is significantly higher than in other patients [28], but some studies have reported that 
the body mass index (BMI) of patients with and without PC was similar and the mean BMI in both groups was not statistically significant [26]. Diabetes mellitus (DM) as a prevalent underlying disease in different societies has always been a factor in the occurrence of varied morbidity and mortality. Relative risk rates for CVD in adults with DM have been reported to be between 1 and 3 times for men and from 2 to 5 times more for women than adults without DM [29]. DM patients are also more likely to have pulmonary disease than other patients with associated illnesses. In one study, 123 patients with DM, who were candidates for a surgical procedure, showed that $14 \%$ of patients had pulmonary disease [30]. But postoperative PC is controversial in these patients. One study reported that the prevalence of PC after cardiac surgery in patients with and without DM was between $10 \%$ and $12 \%$, and it did not have a significant difference [26].

Ultimately, one of the most effective and vital factors is emergency or elective surgery. Indeed, attempting to perform an elective activity, although most of the patients are responsible for the pursuit of illness, but the proper management of the patient by a cardiologist can help prevent an emergency surgery that could increase the risk during operation. In one study that reported postoperative complications in elective and emergency surgery, it was shown that the risk of pneumonia is higher in emergency surgery [31]. However, for each patient, a set of pre-operative factors can be considered, which is why it is the responsibility of the surgeon to have complete coverage of the patient's pre-surgical information.

\section{Perioperative factors}

Although the focus on preoperative factors and patient management can be the most fundamental step in reducing morbidity and mortality of various surgeries - including cardiac artery bypass surgery - the surgical procedure and accompanying events are a critical step in the incidence or absence of morbidity and mortality. In other words, if the patient undergoes surgery in the most stable and remote conditions possible, the main consequence is the outcome of the operation of the surgeon and the clinical team during the operation. Therefore, the importance of perioperative incidents in the occurrence of morbidity and mortality is very important. Although most of the surgical care is similar in practice, CABG surgery, due to both the extent of the surgery and the associated additional procedures, can provide many potential causes for complications such as PC. To further understand the factors affecting pulmonary complications during surgery, these factors are presented in three sections: surgical procedures, anaesthetic procedures, and cardiopulmonary bypass pump.

\section{Surgical procedures}

A review of various studies suggests that the variables involved in CABG surgery, in turn, can activate or limit the pathway of PC. One of the contributing factors is sternotomy incision (SI) that is under contradictory, and various studies have shown inconsistency findings. One study reported PC after SI at nearly 2\% [32]. However, this finding is different from earlier studies [33] that believed that SI had no PC effect. Also, challenges for CPB and cardioplegia and cold effects are still being discussed in other studies. After an aortocoronary bypass graft patient with normothermia exhibited decreases in the alveolus-arterial gradient of $\mathrm{CO}_{2}$, shunt fraction, and PA-a $\mathrm{O}_{2}$, the central temperature did not appear to significantly influence gas exchange, so normothermia is beneficial for the preservation of pulmonary function after CABG [18, 34]. Also, one of the most important factors is the number of vessel grafts that lead to additional severity of surgery, increased surgical duration and duration of anaesthesia, as well as the duration of the CPB pump [35]. In particular, the internal mammary artery (IMA) is one of the sensitivities for increasing the risk of PC [36]. Unfortunately, very few studies have been carried out on this subject, and even in the review articles that have been widely discussed, no clear conclusions have been drawn; for example, in a study titled pleurotomy during IMA harvesting increase post-operative PC, the only final conclusion was that patients undergoing cardiac surgery suffer from pulmonary function after surgery. Pyloromyotomy seems to combine this with increased atherosclerosis and pleural effusion, although it has no effect on clinical outcomes or duration of hospital stay [37]. The abovementioned factors must be performed in all surgical procedures and are considered to be a real part of the surgery and can lead to PC on their own. But in addition, medical errors can lead to irreversible PC. It can be concluded that damage to neural networks, especially the diaphragmatic paralysis, can be expected.

\section{Anaesthesia procedure}

Anaesthesia is the basis for the development of new surgical procedures, and a basic need for heart surgery. Accepting the risk of anaesthesia is the first step in starting an operation and preventing medical errors during anaesthesia, ensuring the success of the surgery and the health of the patient. Of course, in cardiac surgeries, using CPB and anaesthesia are considered to be two active arms of a segment [38]. Efforts to prove the effect of pulmonary ventilation during CPB pump and 
the formation of pulmonary collapse, which will lead to PC, continue to be found in various articles. In fact, lung collapse and damage after reintroduction of post-onset blood flow are factors that cause pulmonary endothelium dysfunction with vascular contraction and increased permeability of the vascular membrane, leading to increased pulmonary, oedema, and hypoxia pressure [39]. Another form of anaesthetic complications is due to anaesthetic drugs that cause PC through immune disorders. In fact, severe changes in immune markers occur both through anaesthetics and after the use of a CPB pump. The use of anaesthetic drugs, especially maintenance drugs, which are given at higher doses, such as propofol, or barbiturates such as thiopental, can provide dramatic changes in the balance of immune markers, which can lead to lung injury [40-42]. Also, the use of opioids such as morphine during anaesthesia is unavoidable because morphine-induced depression, in addition to the involvement of the inflammatory cycle, reduces the activity of macrophages, which subsequently facilitates lung injury. The patient's position is another predisposing factor for lung injury in these patients. CABG candidate patients remain in a supine position for more than $2 \mathrm{~h}$, and the undesired ventilation mentioned above can lead to more harm and to abnormal pulmonary shunt fraction. Generally, the possible damage to the anaesthetic process in patients involves reduction of vital capacity and the functional residual capacity of the lungs and widened alveolar-arterial oxygen gradient, which ultimately leads to hypoxaemia and atelectasis [18, 43-46].

\section{Cardiopulmonary bypass pump}

The use of a CPB pump has led to significant development of open heart surgery. However, in addition to the benefits, this method has many complications, the basis of which is due to systemic inflammatory response syndromes (SIRS) $[47,48]$. Many of the factors involved in the CPB, whether they are substance-related (placement of blood exposed to artificial materials), and independent of matter (surgical trauma, ischaemia - reperfusion of organs, changes in body temperature, and release of endotoxins), create multiple inflammatory responses. The CPB circuit has a common blood flow that is very different from normal endothelium, and this condition leads to undesirable reactions. Activation of the complement system is the primary mechanism that initiates and strengthens the acute inflammatory response. In addition to the increased number of activated leukocytes, the number of leukocyte-platelet pairs also increases in patients undergoing cardiac surgery with CPB. Leukocytes are located not only in the myocardium but also in the lungs and other organs. Isolation of leukocyte is affected by the duration of the aortic and CPB mutual clamping. It is believed that this is one of the major causes of pulmonary damage after onpump surgery [49-51]. Several studies have been carried out to illustrate the effects of the pump on PC. Staton et al. [52], during a study of the consequences of on-pump and off-pump surgery, shown that off-pump patients were extubated significantly faster than on-pump patients. It was also generally stated that off-pump surgery is accompanied by a reduction in the number of postoperative PC and leads to a better exchange of gases. However, for spirometry and lung function, no significant difference is observed. Also, Mack et al. [53], in a study aimed at comparing CABG with and without pump, stated that pneumonia was seen in $3.6 \%$ of on-pump patients and only $2 \%$ of off-pump patients, i.e. significantly lower in off-pump patients. In general, only $4.1 \%$ of offpump patients had postoperative PC, but $9.5 \%$ of on-pump patients showed PC. It should be noted that use of the pump as the main cause of the operation in many surgeries cannot be avoided, and efforts to reduce complications can only be achieved by reducing the duration of the pump.

\section{Postoperative factors}

Although preoperative and operational factors play a major role in the incidence of complications, postoperative care, especially nursing, in the intensive care unit (ICU) can have a very important effect on PC. More than any other complication, mediastinitis can be seen in the ICU or even days after leaving the ICU. In addition, by increasing the duration of hospitalisation, mediastinitis can significantly increase mortality by as much as $28 \%$ [54]. Therefore, taking care of the patient and preventing the occurrence of mediastinitis is one of the basic requirements of postoperative pain.

\section{Conclusions}

Generally, pulmonary complications after cardiac surgery include atelectasis, pleural effusions, pneumonia, pulmonary oedema, cardiogenic pulmonary oedema, acute respiratory distress syndrome, pulmonary embolism, phrenic nerve injury, pneumothorax, sternal wound infection, and mediastinitis, with different outbreaks in patients reported. Although the preoperative, perioperative, and postoperative factors play an important role in the occurrence of these complications, the preoperative factors, as factors that can be adjusted, should be considered more than the others, they should be explained to the patient, and the patient's preoperative assessment should be noted. Also, postoperative care with the goal of reducing 
infections and PC should be addressed by the nursing team.

\section{Acknowledgments}

The present research article was supported by Research Deputy of Shahid Sadoughi University of Medical Sciences, Yazd, Iran

\section{Conflict of interest}

The authors declare no conflict of interest.

\section{References}

1. Reamy BV, Williams PM, Kuckel DP. Prevention of cardiovascular disease. Prim Care 2018; 45: 25-44.

2. Rahmani H, Shahriary A, Sheikhi MA, Ebadi A, Davoodzadeh $\mathrm{H}$. Applications of cardiotoxicity in breast cancer: a meta-analysis. Panminerva Med 2017; 59: 90-6.

3. Lamy A, Devereaux PJ, Prabhakaran D, et al. Five-year outcomes after off-pump or on-pump coronary-artery bypass grafting. N Engl J Med 2016; 375: 2359-68.

4. Mahvar T, Mansoor Soltanzadeh MD, Sabeti F, et al. The effect of positioning on oxygenation after coronary artery bypass graft. Life Sci J 2012; 9: 1426-31.

5. Sabeti F, Soltanzadeh M, Mali S, et al. The effect of semi sitting, supine and lateral positions on results of arterial blood gases and vital signs in patients undergoing coronary artery bypass graft surgery. Life Sci J 2012; 9: 1432-7.

6. Heidari A, Dezfouli FG, Tabatabi K, et al. Combined clopidogrel and aspirin treatment up to surgery dosen't increase the risk of postoperative blood loss and reoperation for bleeding in patients undergoing coronary artery bypass grafting. Int J Pharmaceut Res Allied Sci 2016; 5: 164-7.

7. Kaplan H, Thompson RC, Trumble BC, et al. Coronary atherosclerosis in indigenous South American Tsimane: a cross-sectional cohort study. Lancet 2017; 389: 1730-9.

8. Velazquez EJ, Lee KL, Jones RH, et al. Coronary-artery bypass surgery in patients with ischemic cardiomyopathy. N Engl J Med 2016; 374: 1511-20.

9. Sheikhi MA, Ebadi A, Shahriary A, Davoodzadeh H, Rahmani $\mathrm{H}$. Cardiac surgery anesthesia and systemic inflammatory response. Int J Bioassays 2015; 4: 3648-55.

10. Gupta KK, Ali S, Sanghera RS. Pharmacological options in atherosclerosis: a review of the existing evidence. Cardiol Ther 2019; 8: 5-20.

11. Head SJ, Milojevic M, Daemen J, et al. Mortality after coronary artery bypass grafting versus percutaneous coronary intervention with stenting for coronary artery disease: a pooled analysis of individual patient data. Lancet 2018; 391: 939-48.

12. Dieberg G, Smart NA, King N. On-vs. off-pump coronary artery bypass grafting: a systematic review and metaanalysis. Int J Cardiol 2016; 223: 201-11.

13. Bienz M, Drullinsky D, Stevens LM, Bracco D, Noiseux N. Microcirculatory response during on-pump versus offpump coronary artery bypass graft surgery. Perfusion 2016; 31: 207-15.

14. Chikwe J, Lee T, Itagaki S, Adams DH, Egorova NN. Longterm outcomes after off-pump versus on-pump coronary artery bypass grafting by experienced surgeons. J Am Coll Cardiol 2018; 72: 1478-86.

15. Ubben JF, Lance MD, Buhre WF, Schreiber JU. Clinical strategies to prevent pulmonary complications in car- diac surgery: an overview. J Cardiothorac Vasc Anesth 2015; 29: 481-90.

16. Chen SW, Chang $\mathrm{CH}$, Chu PH, et al. Risk factor analysis of postoperative acute respiratory distress syndrome in valvular heart surgery. J Crit Care 2016; 31: 139-43.

17. Apostolakis E, Filos KS, Koletsis E, Dougenis D. Lung dysfunction following cardiopulmonary bypass. J Cardiac Surg 2010; 25: 47-55.

18. Badenes R, Lozano A, Belda FJ. Postoperative pulmonary dysfunction and mechanical ventilation in cardiac surgery. Crit Care Res Pract 2015; 2015: 420513.

19. Sannakki S, Sannakki D, Echebarria JJ, Patteril M. Preoperative assessment for cardiac surgery. Anaesth Intens Care Med 2018; 19: 339-45.

20. Nicoara A, Swaminathan M. Diastolic dysfunction, diagnostic and perioperative management in cardiac surgery. Curr Opin Anesthesiol 2015; 28: 60-6.

21. Bezanson J, Deaton C, Craver J, Jones E, Guyton RA, Weintraub WS. Predictors and outcomes associated with early extubation in older adults undergoing coronary artery bypass surgery. Am J Crit Care 2001; 10: 383-90.

22. Weiss YG, Merin G, Koganov E, et al. Postcardiopulmonary bypass hypoxemia: a prospective study on incidence, risk factors, and clinical significance. J Cardiothorac Vasc Anesth 2000; 14: 506-13.

23. Firoozabadi MD, Sheikhi MA, Rahmani $H$, et al. Risks of on-pump coronary artery bypass grafting surgery in patients with chronic obstructive pulmonary disease due to sulfur mustard. Adv Dermatol Allergol 2017; 34: 429-32.

24. Ji Q, Zhao H, Mei Y, Shi Y, Ma R, Ding W. Impact of smoking on early clinical outcomes in patients undergoing coronary artery bypass grafting surgery. J Cardiothor Surg 2015; 10: 16.

25. Ngaage DL, Martins E, Orkell E, et al. The impact of the duration of mechanical ventilation on the respiratory outcome in smokers undergoing cardiac surgery. Cardiovasc Surg 2002; 10: 345-50.

26. Ji Q, Mei Y, Wang X, Feng J, Cai J, Ding W. Risk factors for pulmonary complications following cardiac surgery with cardiopulmonary bypass. Int J Med Sci 2013; 10: 1578-83.

27. Musallam KM, Rosendaal FR, Zaatari G, et al. Smoking and the risk of mortality and vascular and respiratory events in patients undergoing major surgery. JAMA Surg 2013; 148: 755-62.

28. De Santo LS, Moscariello C, Zebele C. Implications of obesity in cardiac surgery: pattern of referral, physiopathology, complications, prognosis. J Thorac Dis 2018; 10: 4532-9.

29. Rivellese AA, Riccardi G, Vaccaro O. Cardiovascular risk in women with diabetes. Nutr Metab Cardiovasc Dis 2010; 20: 474-80.

30. Schmeltz LR, DeSantis AJ, Thiyagarajan V, et al. Reduction of surgical mortality and morbidity in diabetic patients undergoing cardiac surgery with a combined intravenous and subcutaneous insulin glucose management strategy. Diabetes Care 2007; 30: 823-8.

31. Kim DK, Yoo KJ, Hong YS, Chang BC, Kang MS. Clinical outcome of urgent coronary artery bypass grafting. J Korean Med Sci 2007; 22: 270-6.

32. Raanani E, Spiegelstein D, Sternik L, et al. Quality of mitral valve repair: median sternotomy versus port-access approach. J Thorac Cardiovasc Surg 2010; 140: 86-90.

33. Ranieri VM, Vitale N, Grasso S, et al. Time-course of impairment of respiratory mechanics after cardiac surgery and cardiopulmonary bypass. Crit Care Med 1999; 27 : 1454-60. 
34. Birdi I, Regragui IA, Izzat MB, et al. Effects of cardiopulmonary bypass temperature on pulmonary gas exchange after coronary artery operations. Ann Thorac Surg 1996; 61: 118-23.

35. Walthall H, Ray S. Do intraoperative variables have an effect on the timing of tracheal extubation after coronary artery bypass graft surgery? Heart Lung 2002; 31 : 432-9.

36. Kurlansky PA, Traad EA, Dorman MJ, Galbut DL, Zucker M, Ebra G. Thirty-year follow-up defines survival benefit for second internal mammary artery in propensity-matched groups. Ann Thorac Surg 2010; 90: 101-8.

37. Wheatcroft $M$, Shrivastava $V$, Nyawo B, Rostron A Dunning J. Does pleurotomy during internal mammary artery harvest increase post-operative pulmonary complications? Interact Cardiovasc Thorac Surg 2005; 4: $143-6$.

38. De Backer D, Dubois MJ, Schmartz D, et al. Microcirculatory alterations in cardiac surgery: effects of cardiopulmonary bypass and anesthesia. Ann Thorac Surg 2009; 88: 1396-403.

39. Andrejaitienė J, Širvinskas E, Bolys R. The influence of cardiopulmonary bypass on respiratory dysfunction in early postoperative period. Medicina 2004; 40: 7-12.

40. Haroun-Bizri S, Khoury SS, Chehab IR, Kassas CM, Baraka $A$. Does isoflurane optimize myocardial protection during cardiopulmonary bypass? J Cardiothorac Vasc Anesth 2001; 15: 418-21.

41. Likhvantsev VV, Landoni G, Levikov DI, Grebenchikov OA, Skripkin YV, Cherpakov RA. Sevoflurane versus total intravenous anesthesia for isolated coronary artery bypass surgery with cardiopulmonary bypass: a randomized trial. J Cardiothorac Vasc Anesth 2016; 30: 1221-7.

42. Apostolakis E, Filos KS, Koletsis E, Dougenis D. Lung dysfunction following cardiopulmonary bypass. J Card Surg 2010; 25: 47-55.

43. Hedenstierna G, Strandberg A, Brismar B, Lundquist $H$, Svensson L, Tokics L. Functional residual capacity, thoracoabdominal dimensions, and central blood volume during general anesthesia with muscle paralysis and mechanical ventilation. Anesthesiology 1985; 62: 247-54.

44. Brismar B, Hedenstierna G, Lundquist $H$, Strandberg A, Svensson L, Tokics L. Pulmonary densities during anesthesia with muscular relaxation: a proposal of atelectasis. Anesthesiology 1985; 62: 422-8.

45. Santos LM, Santos VC, Santos SR, Malbouisson LM, Carmona MJ. Intrathecal morphine plus general anesthesia in cardiac surgery: effects on pulmonary function, postoperative analgesia, and plasma morphine concentration. Clinics 2009; 64: 279-85.

46. Firoozabadi MD, Shahriary A, Rahmani H. Mustard lung anesthesia: general anesthesia in patients with chronic obstructive pulmonary disease due to sulphur mustard exposure. Minerva Pneumol 2017; 56: 254-7.

47. Hessel II EA. History of cardiopulmonary bypass (CPB). Best Pract Res Clin Anaesthesiol 2015; 29: 99-111.

48. Lannemyr L, Bragadottir G, Krumbholz V, Redfors B, Sellgren J, Ricksten SE. Effects of cardiopulmonary bypass on renal perfusion, filtration, and oxygenation in patients undergoing cardiac surgery. Anesthesiology 2017; 126: 205-13.

49. Evora PR, Bottura C, Arcêncio L, Albuquerque AA, Évo ra PM, Rodrigues AJ. Key points for curbing cardiopulmonary bypass inflammation. Acta Cir Bras 2016; 31 : 45-52.
50. Levy JH, Tanaka KA. Inflammatory response to cardiopulmonary bypass. Ann Thorac Surg 2003; 75: S715-20.

51. Justus G, Walker C, Rosenthal LM, Berger F, Miera O, Schmitt KR. Immunodepression after CPB: cytokine dynamics and clinics after pediatric cardiac surgery a prospective trial. Cytokine 2019: 122: 1510018.

52. Staton GW, Williams WH, Mahoney EM, et al. Pulmonary outcomes of off-pump vs on-pump coronary artery bypass surgery in a randomized trial. Chest 2005; 127 : 892-901.

53. Mack MJ, Pfister A, Bachand D, et al. Comparison of coronary bypass surgery with and without cardiopulmonary bypass in patients with multivessel disease. J Thorac Cardiovasc Surg 2004; 127: 167-73.

54. Dubert M, Pourbaix A, Alkhoder S, et al. Sternal wound infection after cardiac surgery: management and outcome. PLoS One 2015; 10: e0139122. 